\title{
Pengaruh Penambahan Waste Glass Sebagai Agregat Kasar Terhadap Kuat Tekan Beton
}

\author{
Sri Rejeki Laku Utami ${ }^{\mathrm{a},}$, , Muh Zaini ${ }^{\mathrm{b}}$, Adib Wajyu Hidayat ${ }^{\mathrm{b}}$ \\ ${ }^{a}$ Program Pascasarjana, Departemen Teknik Sipil dan Lingkungan, Universitas Gadjah Mada, Yogyakarta, 565223, Indonesia \\ ${ }^{\mathrm{b}}$ Departemen Teknik Sipil dan Lingkungan, Universitas Gadjah Mada, Yogyakarta, 565223, Indonesia
}

Keywords:

Waste Glass Concrete (BWG)

Compressive strength

Kata kunci:

Beton Waste Glass (BWG)

Kuat tekan

\begin{abstract}
This research aims to utilize glass waste as the basic material of coarse aggregate in the concrete mix used to reduce glass waste. This research uses 15 specimens with $150 \times 300 \mathrm{~mm}$ in dimensions. The test results of normal concrete $(B N)$ at 7,14 , and 28 days were $20.95 \mathrm{~N} / \mathrm{mm}$, $28.31 \mathrm{~N} / \mathrm{mm}$, and $34.54 \mathrm{~N} / \mathrm{mm}$. The BWG 1 at 7,14 , and 28 days was $24.35 \mathrm{~N} / \mathrm{mm}, 25.48 \mathrm{~N} / \mathrm{mm}$, and $33.97 \mathrm{~N} / \mathrm{mm}$. BWG $\mathrm{G}_{2}$ at 7,14 , and 28 days of $17.55 \mathrm{~N} / \mathrm{mm}^{2}, 23.78 \mathrm{~N} / \mathrm{mm}$, and $29.44 \mathrm{~N} / \mathrm{mm}$. Waste glass $\left(B W G_{3}\right)$ at 7,14 , and 28 days of $20.38 \mathrm{~N} / \mathrm{mm}^{2}, 20.95 \mathrm{~N} / \mathrm{mm}$, and $26.04 \mathrm{~N} / \mathrm{mm}$. $B W G_{4}$ at 7,14 , and 28 were $13.02 \mathrm{~N} / \mathrm{mm}, 19.82 \mathrm{~N} / \mathrm{mm}$, and $22.08 \mathrm{~N} / \mathrm{mm}$. Comparison of the compressive strength of normal concrete with waste glass concrete at the age of 7 days showed that $B W G_{1}$ increased around $16 \%$. As for other test specimens, there was a decrease in compressive strength compared to $B N$ were the results for $B W_{2}, B W_{3}, B W_{4}(16 \%, 3 \%$, and $38 \%$ ). At 14 days shows that the $B W G_{1}, B W G_{2}, B W G_{3}$, and $B W G_{4}$ decrease by $10 \%, 16 \%, 26 \%$, and $30 \%$. At 28 days showed the $B W G_{1}, B W G_{2}, B W G_{3}$, and $B W G_{4}$ decrease of $2 \%, 15 \%, 25 \%$, and $36 \%$ compared to $B N$.
\end{abstract}

\begin{abstract}
ABSTRAK
Penelitian ini bertujuan untuk memanfaatkan limbah kaca sebagai bahan dasar agregat kasar dalam campuran beton yang digunakan untuk mereduksi limbah kaca. Penelitian ini menggunakan 15 benda uji dengan dimensi $150 \times 300 \mathrm{~mm}$. Hasil pengujian beton normal (BN) pada umur 7, 14, dan 28 hari adalah 20,95 N/mm, 28,31 N/mm, dan 34,54 N/mm. BWG 1 pada hari ke 7, 14, dan 28 adalah 24,35 N/mm, 25,48 N/mm, dan 33,97 N/mm. BWG 2 pada 7, 14, dan 28 hari sebesar 17,55 N/mm², 23,78 N/mm, dan 29,44 N/mm. BWG 3 pada 7, 14, dan 28 hari sebesar 20,38 N/mm², 20,95 N/mm, dan 26,04 N/mm. BWG 4 pada 7, 14, dan 28 adalah $13,02 \mathrm{~N} / \mathrm{mm}, 19,82 \mathrm{~N} / \mathrm{mm}$, dan 22,08 N/mm. Perbandingan kuat tekan beton normal dengan beton limbah kaca pada umur 7 hari menunjukkan bahwa $\mathrm{BWG}_{1}$ meningkat sekitar $16 \%$. Sedangkan untuk benda uji lainnya terjadi penurunan kuat tekan dibandingkan dengan BN yaitu pada hasil $\mathrm{BW}_{2}, \mathrm{BW}_{3}, \mathrm{BW}_{4}(16 \%, 3 \%$, dan $38 \%)$. Pada 14 hari menunjukkan bahwa $\mathrm{BWG}_{1}$, $\mathrm{BWG}_{2}, \mathrm{BWG}_{3}$, dan $\mathrm{BWG}_{4}$ mengalami penurunan sebesar $10 \%, 16 \%, 26 \%$, dan $30 \%$. Pada hari ke 28 menunjukkan penurunan $\mathrm{BWG}_{1}, \mathrm{BWG}_{2}, \mathrm{BWG}_{3}$, dan $\mathrm{BWG}_{4}$ sebesar $2 \%, 15 \%, 25 \%$, dan $36 \%$ dibandingkan dengan $\mathrm{BN}$.
\end{abstract}

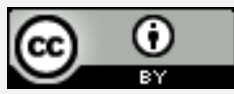

This is an open access article under the CC-BY license.

\section{Pendahuluan}

Pembangunan berperan penting bagi suatu negara, Pembangunan bisa berupa pembangunan fisik maupun non fisik. pembangunan fisik di-era sekarang ini banyak sekali menggunakan beton,mulai dari beton konvensional, beton ready mix ataupun beton pracetak (precast). beton di minati karena mudah dibentuk sesuai dengan desain yang diinginkan dan memiliki nilai kuat tekan lebih tinggi

"Corresponding author.

E-mail: udhitami@gmail.com

https://doi.org/10.21831/inersia.v17i2.41223

Received 10 June 2021; Revised 28 December 2021; Accepted 29 December 2021 Available online 31 December 2021 dibandingkan kayu atapun bambu. Beton didefiniskan sebagai campuran dari bahan penyusunnya yang terdiri dari bahan hidrolik (portland cement), agregat kasar, agregat halus, dan air dengan atau tanpa menggunakan bahan tambah (admixture atau additive) SNI 2847:2013 [1]-[3].

Pemanfaatan bahan limbah dan analisis material penyusun telah diteliti [4]-[7] kaca sebagai bahan dasar agregat 
kasar dalam campuran beton digunakan untuk mengurangi limbah kaca tersebut. Kaca dibuat dengan mencampur pasir, abu soda, dan kapur/oksida timah. Tiga bahan dasar dicampur dengan cullet (pecahan kaca), dolomite dan saltcake, kemudian dilelehkan dalam tungku pembakaran, panas yang sangat tinggi, membuat bahan-bahan itu menyatu dan mencair [8], [9].

Limbah kaca ini mempunyai ukuran beragam dan rata-rata mempunyai bentuk memanjang. Penelitian ini ingin memanfaatkan limbah pecahan kaca sebagai bahan pengganti agregat kasar (Batu Split) dalam komposisi campuran beton. Adukan campuran beton memakai bahan batu split, pasir muntilan, semen gresik, dan air sumur sebagai bahan dasar campuran beton serta menggunakan asumsi perbandingan 1 Semen, 3 Agregat Halus, dan 3 Agregat Kasar (1:3:3) dengan Faktor Air Semen (f.a.s) 0,58 untuk mencapai mutu rencana yaitu mutu beton $\mathrm{K}$ 225 dengan memakai cetakan berbentuk silinder berukuran $150 \mathrm{~mm}$ x $300 \mathrm{~mm}$ dengan jumlah 15 buah, Penambahan waste glass untuk menggantikan Agregat Kasar Batu Split pada adukan beton memiliki persentase penambahan $0 \%, 5 \%, 15 \%, 30 \%$, dan $50 \%$ dengan 3 buah sample pada tiap-tiap variannya, pengujian kuat tekan beton dilakukan saat beton berumur 7 hari,14 hari dan 28 hari.

\subsection{Limbah Kaca Penyusun Beton}

Inovasi beton dengan caramemanfaatkan limbah kaca sebagai bahan campuran beton mulai berkembang [8], [10]-[13], pemanfaatan waste glass digunakan sebagai subtitusi untukagregat halus, agregat kasar, dan bahan pencampur lainnya. Dari penelitian tentang pemanfaatan limbah kaca bertujuan untuk mendaur ulang/ menggunakan kaca yang sudah berbentuk limbah mulai dari pecahan kaca plat/botol kaca/ dan limbah kaca berbetuk lainnya.

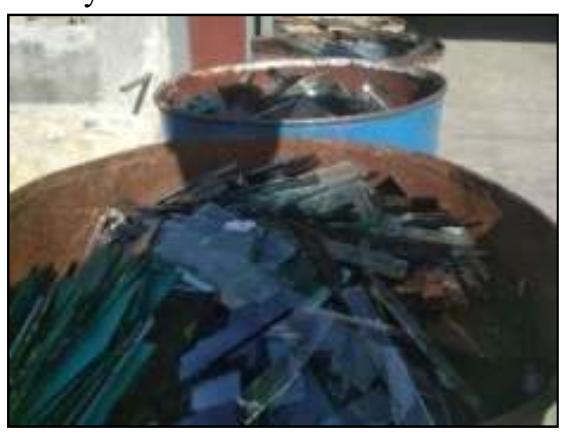

Gambar 1. Limbah kaca

\subsection{Metode Pelaksanaan Penelitian}

Pencampuran bahan-bahan penyusunbeton dilakukan agar diperoleh suatu komposisi yang solid dari bahan-bahan penyusun berdasarkan rancangan campuran beton. Sebelum diimplementasikan dalam pelaksanaan konstruksi di lapangan, pencampuran bahan-bahan dapat dilakukan di laboratorium. Agar tetap terjaga konsistensi rancangannya, tahapan lebih lanjut dalam pengolahan beton perlu diperhatikan. Komposisi yang baik akan menghasilkan kuat tekan yang tinggi, tetapi jika pelaksanaannya tidak dikontrol dengan baik, kemungkinandihasilkannya beton yang tak sesuai dengan rencana akan semakin besar [14], [15].

Berikut adalah beberapa tahapan dalam pelaksanaan pembuatan beton.

1. Persiapan

2. Pengadukan (Mixing)

3. Penuangan atau pengecoran (Placing)

4. Perawatan (Curing)

5. pengujian.

\subsection{Kuat Tekan}

Untuk merencanakan sebuah komponen struktur beton, biasanya diasumsikan bahwa beton akan menopang tegangan tekan dan bukannya tegangan tarik. Oleh sebab itu kuat tekan beton pada dasarnya dijadikan pedoman untuk menentukan mutu atau kualitas suatu material beton. Umumnya sifat mekanik beton yang lainnya, dapat diperkirakan berdasarkan pada kuat tekan beton. Untuk menentukan besarnya kuat tekan beton dapat dilakukan uji kuat tekan dengan mengacu pada standar ASTM C39/C39M-20 'Standard Test Method for Compressive Strength of Cylindrical Concrete Specimens" [16]. Benda uji yang sering digunakan di negara Indonesia adalah benda uji berupa silinder berdiameter $150 \mathrm{~mm}$ dan tinggi $300 \mathrm{~mm}$.

Beberapa faktor yang mempengaruhi kuat tekan, antara lain: jenis dan kualitas semen yang dipakai, jenis dan tekstur bidang permukaan agregat, pemakaian dan kualitas air, Faktor air semen,umur beton saat diuji serta kondisi kelembapan udara saat masaperawatan benda uji.

\subsection{Nilai FAS (Faktor Air Semen)}

Faktor air semen (f.a.s.) adalah perbandingan antara berat air dengan berat semen yang digunakan dalam campuran beton. Tidak hanya pada beton mutu rendah, pada beton mutu tinggi, w/c bisa diartikan sebagai water to cementitious ratio yang berarti rasio atau perbandingan berat air terhadap berat semen dan aditif cementitious yang umumnya ditambahkan dalam campuran beton mutu tinggi. Adapun untuk grafik FAS dapat dlihat pada Gambar 2. 


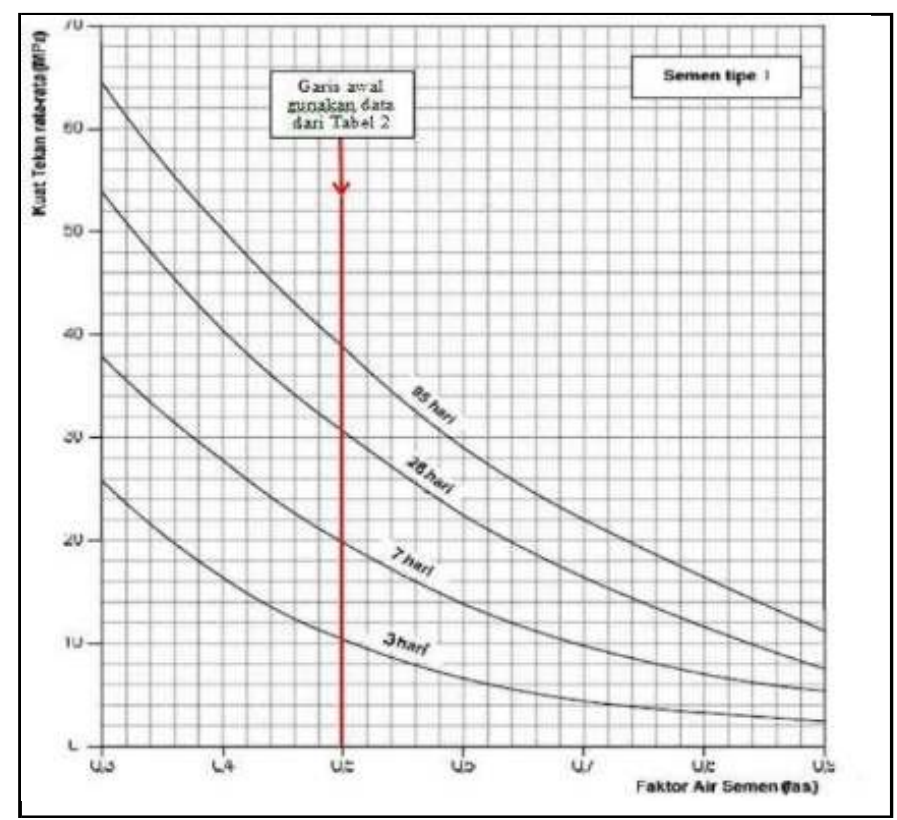

Gambar 2. Kuat tekan dan f.a.s.

Setelah diketahui nilai fas dari grafik diatas, maka dilanjutkan dengan menentukan faktor air semen (fas) maksimum yang dapat ditentukan dari Tabel 1 .
Persyaratan Fas dan Jumlah Semen Minimum untuk BerbagaiPembetonan dan Lingkungan Khusus.

Tabel 1. Syarat f.a.s. dan jumlah semen minimum untuk lingkungan khusus

\begin{tabular}{|c|c|c|}
\hline Jenis pembetonan & $\begin{array}{l}\text { Jumlah semen minimum } \\
\text { per- } \mathrm{m}^{3} \text { beton }(\mathrm{kg})\end{array}$ & $\begin{array}{l}\text { Nilai f.a.s. } \\
\text { maksimum }\end{array}$ \\
\hline \multicolumn{3}{|l|}{ Beton di dalam ruang bangunan } \\
\hline Keadaan keliling non korosif & 275 & 0,6 \\
\hline $\begin{array}{l}\text { Keadaan keliling korosif disebabkan } \\
\text { oleh kondensasi atau uap korosif }\end{array}$ & 325 & 0,52 \\
\hline \multicolumn{3}{|l|}{ Beton di luar ruangan bangunan } \\
\hline $\begin{array}{l}\text { Tidak terlindung dari hujan dan terik } \\
\text { matahari langsung }\end{array}$ & 325 & 0,6 \\
\hline $\begin{array}{l}\text { Terlindung dari hujan dan terik } \\
\text { matahari langsung }\end{array}$ & 275 & 0,6 \\
\hline \multicolumn{3}{|l|}{ Beton masuk ke dalam tanah } \\
\hline $\begin{array}{l}\text { Mengalami keadaan basah dan } \\
\text { kering berganti-ganti }\end{array}$ & 325 & 0,52 \\
\hline $\begin{array}{l}\text { Mendapat pengaruh sulfat dan alkali } \\
\text { dari tanah }\end{array}$ & & Tabel 3.10 \\
\hline $\begin{array}{l}\text { Beton yang kontinu berhubungan } \\
\text { dengan air tawar dan air laut }\end{array}$ & & Tabel 3.11 \\
\hline
\end{tabular}

\subsection{Persentase Agregat Halus}

Agregat halus adalah pasir halus yang memiliki ukuran butir maksimal $5 \mathrm{~mm}$. Salah satu kegunaan agregat halus adalah sebagai bahan pengisi campuran beton. Untuk memperoleh kualitas beton yang baik, perlu dihitung jumlah agregat halus yang membentuk campuran beton tersebut. Adapun untuk grafik prosentase agregat halus dapat dilihat pada Gambar 3 Persen Pasir Terhadap Kadar Total Agregat yang Dianjurkan Untuk Ukuran Butir Maksimum $10 \mathrm{~mm}$ [17]. 


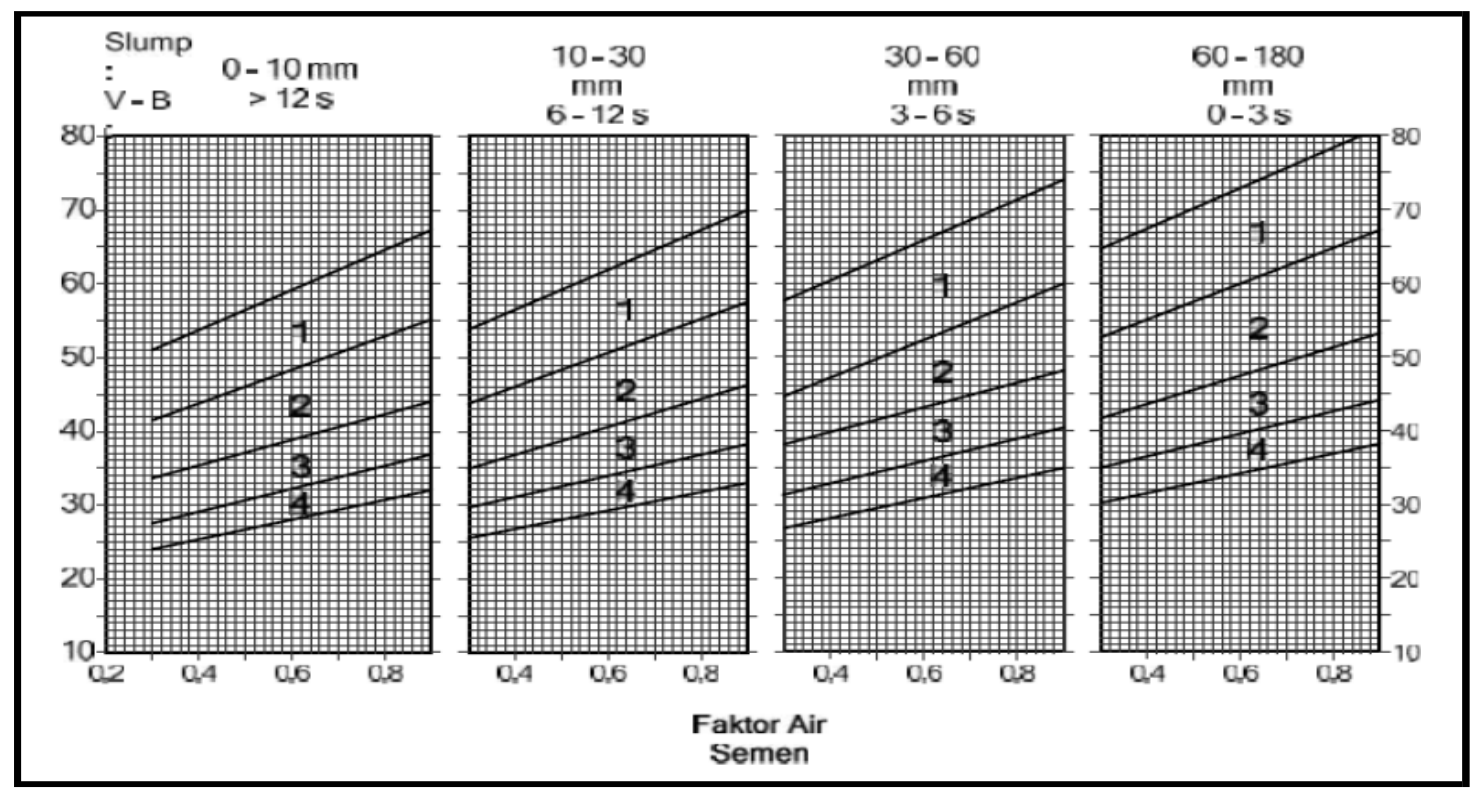

Gambar 3. Persen Pasir Terhadap Kadar Total Agregat yang Dianjurkan Untuk Ukuran Butir Maksimum 10mm

\subsection{Campuran Beton}

Pencampuran bahan-bahan penyusun beton dilakukan agar diperoleh suatu komposisi yang solid dari bahanbahan penyusun berdasarkan rancangan campuran beton. Sebelum diimplementasikan dalam pelaksanaan konstruksi di lapangan, pencampuran bahan-bahan dapat dilakukan di laboratorium. Agar tetap terjaga konsistensi rancangannya, tahapan lebih lanjut dalam pengolahan beton perlu diperhatikan. Komposisi yang baik akan menghasilkan kuat tekan yang tinggi, tetapi jika pelaksanaannya tidak dikontrol dengan baik, kemungkinan dihasilkannya beton yang tak sesuai dengan rencana akan semakin besar.

Setelah didapatkan komposisi yang direncanakan untuk kuat tekan tertentu, maka proses selanjutnya adalah pencampuran di lapangan Komposisinya disesuaikan dengan kapasitas alat aduk. Secara umum Pengadukan dilakukan sampai didapatkan suatu sifat yang plastis dalam campuran beton segar. Indikasinya adalah warna adukan merata, kelecakan yang cukup, dan tampak homogeny.

Selama proses pengadukan, harus dilakukan pendataan rinci mengenai meliputi: jumlah batch-aduk yang dihasilkan, proporsi material, perkiraan lokasi dari penuangan akhir, waktu dan tanggal pengadukan serta penuangan.
Untuk menghindari terjadinya segregasi dan bleeding, ada beberapa hal yang perlu diperhatikan dalam penuangan beton. Hal-hal yang perlu diperhatikan antara lain:

1. Campuran yang akan dituangkan harus ditempatkan sedekat mungkin dengan cetakan akhir untuk mencegah segregasi karena penanganan kembali atau pengaliran adukan.

2. Pembetonan harus dilaksanakan dengan kecepatan penuangan yang diatur sedemikian rupa sehingga campuran beton selalu dalam keadaan plastis dandapat mengalir dengan mudah ke dalam rongga di antara tulangan.

3. Campuran beton yang telah mengeras atau yang telah terkotori oleh material asing tidak boleh dituang ke dalam struktur.

4. Campuran beton yang setengah mengeras atau telah mengalami penambahan air tidak boleh dituangkan, kecuali telah disetujui oleh pengawas ahli.

5. Beton yang dituangkan harus dipadatkan dengan alat yang tepat secara sempurna dan harus diusahakan secara maksimal agar dapat mengisi semua rongga beton.

\subsection{Perawatan (Curing)}

Perawatan (Curing) bermaksud untuk menghindari panas hidrasi yang tidakdi kehendaki yang disebabkan oleh suhu. Cara dan bahan serta alat yang dipakaiuntuk perawatan akan menentukan sifat dari beton hasilkan, terutama dari sisi kekuatannya. Waktu-waktu untuk merawat beton pun harus terjadwal dengan benar. Beton akan mengalami pengerasan secara sempurna adalah setelah 28 hari, sehingga pada hari-hari sebelumnya akan mempunyai kuat tekan yang berbeda. Perawatan dengan pembasahan 
bisa dilakukan di laboratorium ataupun di lapangan. Pekerjaan perawatan dengan pembasahan ini dapat dilakukan dengan beberapa cara yaitu:

1. meletakkan beton segar dalam ruangan yang lembab.

2. meletakkan beton segar dalam air.

3. Menyelimuti permukaan beton dengan air.

4. Menyelimuti permukaan beton dengan karung basah.

5. Menyirami permukaan beton secara kontinu.

\subsection{Pengujian Beton}

Pengambilan contoh uji dan pengujian dalam pelaksanan pekerjaan beton secara umum dapat dibagi menjadi tiga kegiatan: pengujian material penyusun beton, pengujian beton segar, pengujian beton keras Pengujian beton dilakukan setelah masa perawatan benda uji. Benda uji yang digunakan dapat berupa silinder, balok ataupun kubus dengan ukuran sesuai dengan yang disyaratkan. standart pengujian kuat tekan beton dengan silinder.

\section{Metode}

\subsection{Bahan Penelitian}

Bahan bahan yang dipakai dalam penelitian ini dapat diuraikan sebagai berikut: (a) Beton yang digunakanadalah mutu $19 \mathrm{MPa}$ dan slump $10 \pm 2 \mathrm{~cm}$. Pemilihan sesuai dengan peraturan SNI 2834-2000 [18] dan SNI 28472013 [1] . Bahan campuran yang digunakan adalah limbah kaca atau Beton Water Glass (BWG) menggunakan silinder 15 x $30 \mathrm{~mm}$ sejumlah 15 benda uji. Beton Agregat Kasar Limbah Kaca, uji kuat tekan beton dengan memakai campuran pecahan kaca untuk agregat kasarnya mengalami penurunan seiring penambahan persentase pecahan kaca,oleh karena itu peneliti akan melakukan treatment pemecahan tidak beraturan pada limbah kaca dengan tujuan untuk meningkatkan nilai kuat tekan beton. Karena sifat kaca yang tahan terhadap zat kimia dan mudah pecah, pelaksanan treatment pada limbah kaca ini tidak bisa memakai bahan kimia cair untuk merubah karakteristik kaca tetapi peneliti akan lebih mengarah pada cara pemecahan limbah kaca dan bentuk pecahan kaca yang tidak beraturan.

\subsection{Peralatan Pengujian}

Alat yang dipakai dalam pengujian ini adalah Mesin Uji Tekan Beton, Slump Test (kerucut Abram's) [19].

\subsection{Benda Uji}

Dalam pembuatan benda uji persentase penambahan limbah pecahan kaca (waste glass) dalam campuran beton untuk penganti agregat kasar (Batu Split) adapun presentase penambahanya adalah $0 \%, 5 \%, 15 \%, 30 \%$, dan $50 \%$. Benda uji pada penelitian ini berbentuk silinder dengan tinggi $300 \mathrm{~mm}$ danlebar $150 \mathrm{~mm}$, dibuat 3 sampel dari setiap varian dengan total seluruh sampel benda uji berjumlah 15 buah, pengujian yang dilakukan adalah uji kuat tekan beton. Pembuatan perencanaan benda uji bertujuan agar sampel yang nantinya akan di ujikan jumlahnya terperinci sekaligus menjadi pedoman peneliti untuk membuat benda uji beton, tiap-tiap varian campuran beton dibuat 3 sample untuk tiap sampel di ujikan nilai kuat tekannya ketika beton dalam umur tertentu.

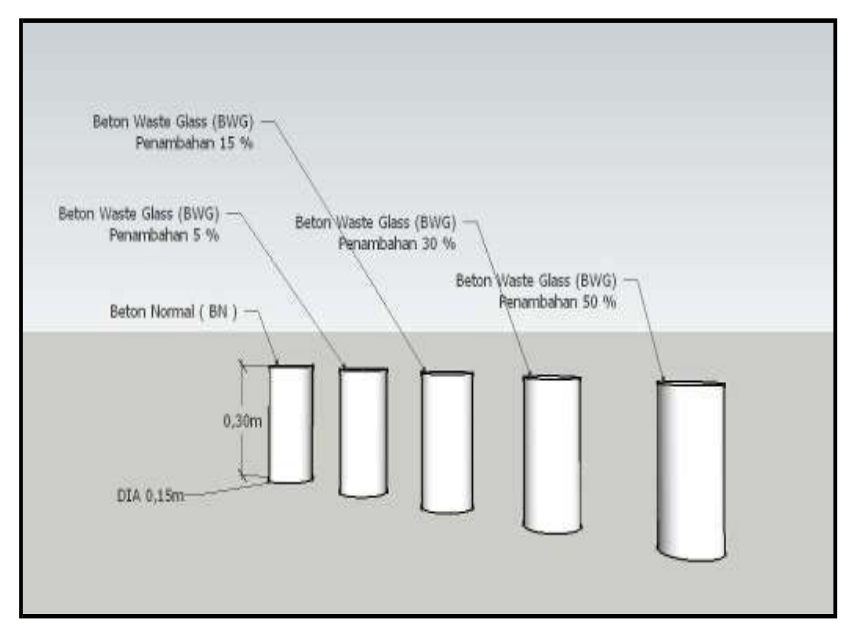

Gambar 3. Penambahan waste glass pada beton

Seanjutnya, untuk sampel pada benda uji mengacu kepada Tabel 2.

Tabel 2. Jumlah benda uji

\begin{tabular}{ccccc}
\hline Bentuk uji & $\begin{array}{c}\text { Agregat halus } \\
\text { (pasir Muntilan) }\end{array}$ & $\begin{array}{c}\text { Agregat kasar } \\
\text { (Batu split) }\end{array}$ & $\begin{array}{c}\text { Agregat kasar } \\
\text { (pecahan kaca) }\end{array}$ & $\begin{array}{c}\text { Jumlah } \\
\text { benda uji }\end{array}$ \\
\hline Silinder & $100 \%$ & $100 \%$ & $0 \%$ & 3 \\
Silinder & $100 \%$ & $95 \%$ & $5 \%$ & 3 \\
Silinder & $100 \%$ & $85 \%$ & $15 \%$ & 3 \\
Silinder & $100 \%$ & $70 \%$ & $30 \%$ & 3 \\
Silinder & $100 \%$ & $50 \%$ & $50 \%$ & 3 \\
& & Jumlah & & $\mathbf{1 5}$ \\
\hline
\end{tabular}


Tabel 3. Estimasi Harga Satuan untuk Benda Uji

\begin{tabular}{cccc}
\hline Kode Benda uji & Volume material & Satuan & Total harga (Rp) \\
\hline BN & 50,341 & $\mathrm{~kg}$ & $17.401,00$ \\
$\mathrm{BWG}_{1}$ & 50,341 & $\mathrm{~kg}$ & $17.353,00$ \\
$\mathrm{BWG}_{2}$ & 50,341 & $\mathrm{~kg}$ & $17.257,00$ \\
$\mathrm{BWG}_{3}$ & 50,341 & $\mathrm{~kg}$ & $17.113,00$ \\
$\mathrm{BWG}_{4}$ & 50,341 & $\mathrm{~kg}$ & $16.920,00$ \\
\hline
\end{tabular}

Kebutuhan material dalam penelitian ini adalah sebagai berikut:

1. Jika menggunakan benda uji berupa silinder dengan ukuran silinder (Ø: $150 \mathrm{~mm} /$ 0,15 m, h: $300 \mathrm{~mm} / 0,30$ m) maka dapat dihitung menggunakan persamaan sebagai berikut:

$$
\begin{aligned}
\pi . r^{2} . t & =3,14 \times 0,075^{2} \times 0,30 \\
& =0,005299 \mathrm{~m}^{3}
\end{aligned}
$$

2. menghitung kebutuhan material beton tiap satu silinder.

Proporsi Campuran untuk $1 \mathrm{~m}^{3}$ beton:

Semen Portland $=353,448 \mathrm{~kg} / \mathrm{m} 3$, Air $=205 \mathrm{~kg} / \mathrm{m} 3$, Agregat Halus $=962,772 \mathrm{~kg} / \mathrm{m} 3$, Agregat Kasar $=$ $853,779 \mathrm{~kg} / \mathrm{m}^{3}$.

Selanjutnya, setiap $1 \mathrm{~m}^{3}$ membutuhkan berat total matrial yakni sebanyak $2375 \mathrm{~kg} / \mathrm{m}^{3}$ yaitu Proporsi Campuran untuk $0,00529 \mathrm{~m}^{3}$ beton : Semen Portland $=$ $1,873 \mathrm{~kg} / \mathrm{m}^{3}$, Air $=1,086 \mathrm{~kg} / \mathrm{m}^{3}$, Agregat Halus $=5,102$ $\mathrm{kg} / \mathrm{m}^{3}$, Agregat Kasar $=4,524 \mathrm{~kg} / \mathrm{m}^{3}$.

\subsection{Perhitungan Estimasi Biaya}

Untuk mengetahuai perkiraan biaya permatrial sekaligus pembanding dari segi biaya antara beton normal dengan beton pecahan kaca maka penulis membuat rincian tabel perhitungan etimasi biaya material untuk $0,021195 \mathrm{~m}^{3}$ campuran beton adapun estimasi perhitungan pada Tabel 3.

Penambahan komposisi pecahan kaca pada campuran beton, maka semakin murah untuk biaya pembuatan beton uji.adapun perincian estimasi biaya pada Tabel 3 .

\subsection{Pengujian Kuat Tekan Benda Uji}

Setelah benda uji memasuki umur beton pada 7 hari 5 buah sampel benda uji bisa di tes untuk mengetahui nilai kuat tekannya, selanjutnya 5 sample pada beton ketika sudah berumur 14 hari dan sisanya 5 sample setelah beton berumur 28 hari. Pengujian dilakukan menggunakan mesin kuat tekan hidrolik.

\begin{tabular}{|c|c|c|c|c|c|c|}
\hline $\begin{array}{c}\text { Kode } \\
\text { Benda } \\
\text { uji }\end{array}$ & Material & $\begin{array}{l}\text { Volume } \\
\text { material }\end{array}$ & Satuan & $\begin{array}{c}\text { Massa } \\
\text { jenis } \\
\left(\mathrm{kgm}^{3}\right)\end{array}$ & $\begin{array}{l}\text { Harga satuan } \\
\text { per-m }{ }^{3}(\mathrm{Rp})\end{array}$ & $\begin{array}{l}\text { Total Harga } \\
\text { (Rp) }\end{array}$ \\
\hline \multirow{6}{*}{ BN } & Semen & 7,492 & $\mathrm{~kg}$ & 31,50 & $4.410 .000,00$ & $10.488,00$ \\
\hline & Air & 4,345 & $\mathrm{~kg}$ & 1000 & $10.000,00$ & 43,00 \\
\hline & Ag. Halus (pasir Muntilan) & 20.407 & $\mathrm{~kg}$ & 1400 & $285.000,00$ & $4.154,00$ \\
\hline & Ag. Kasar (Batu Split) & 18,097 & $\mathrm{~kg}$ & 1800 & $270.000,00$ & $2.715,00$ \\
\hline & Ag. Halus (Pecahan kaca) & 0,000 & $\mathrm{~kg}$ & 2579 & $250.000,00$ & 0,00 \\
\hline & Total volume material & 50,340 & $\mathrm{Kg}$ & \multicolumn{2}{|c|}{ Total harga } & $17.401,00$ \\
\hline \multirow{6}{*}{$\mathrm{BWG}_{1}$} & Semen & 7,492 & $\mathrm{~kg}$ & 3150 & $4.410 .000,00$ & $10.488,00$ \\
\hline & Air & 4,345 & $\mathrm{~kg}$ & 1000 & $10.000,00$ & 43,00 \\
\hline & Ag. Halus (pasir Muntilan) & 20,407 & $\mathrm{~kg}$ & 1400 & $285.000,00$ & $4.154,00$ \\
\hline & Ag. Kasar (Batu Split) & 17,192 & $\mathrm{~kg}$ & 1800 & $270.000,00$ & $2.579,00$ \\
\hline & Ag. Halus (Pecahan kaca) & 0,905 & $\mathrm{~kg}$ & 2579 & $250.000,00$ & 88,00 \\
\hline & Total volume material & 50,340 & & \multicolumn{2}{|c|}{ Total harga } & $17.353,00$ \\
\hline \multirow{6}{*}{$\mathrm{BWG}_{2}$} & Semen & 7,492 & $\mathrm{~kg}$ & 3150 & $4.410 .000,00$ & $10.488,00$ \\
\hline & Air & 4,345 & $\mathrm{~kg}$ & 1000 & $10.000,00$ & 43,00 \\
\hline & Ag. Halus (pasir Muntilan) & 20,407 & $\mathrm{~kg}$ & 1400 & $285.00,00$ & $4.154,00$ \\
\hline & Ag. Kasar (Batu Split) & 15,382 & $\mathrm{~kg}$ & 1800 & $270.000,00$ & $2.307,00$ \\
\hline & Ag. Halus (Pecahan kaca) & 2,715 & $\mathrm{~kg}$ & 2579 & $250.000,00$ & 263,00 \\
\hline & Total volume material & 50,340 & $\mathrm{~kg}$ & \multicolumn{2}{|c|}{ Total harga } & $17.257 .000,00$ \\
\hline
\end{tabular}

Tabel 4. Perhitungan Estimasi Biaya Beton Normal dan Beton BW 


\begin{tabular}{clrrrrr}
\hline $\begin{array}{c}\text { Kode } \\
\begin{array}{c}\text { Benda } \\
\text { uji }\end{array}\end{array}$ & \multicolumn{1}{c}{ Material } & $\begin{array}{r}\text { Volume } \\
\text { material }\end{array}$ & Satuan & $\begin{array}{c}\text { Massa } \\
\text { jenis } \\
\left(\mathrm{kgm}^{3}\right)\end{array}$ & $\begin{array}{r}\text { Harga satuan } \\
\text { per- }{ }^{3}(\mathrm{Rp})\end{array}$ & $\begin{array}{r}\text { Total Harga } \\
(\mathrm{Rp})\end{array}$ \\
\hline & Semen & 7,492 & $\mathrm{~kg}$ & 3150 & $4.410 .000,00$ & $10.488,00$ \\
& Air & 4,345 & $\mathrm{~kg}$ & 1000 & $10.000,00$ & 43,00 \\
$\mathrm{BWG}_{3}$ & Ag. Halus (pasir Muntilan) & 20,407 & $\mathrm{~kg}$ & 1400 & $285.000,00$ & \\
& Ag. Kasar (Batu Split) & 12,668 & $\mathrm{~kg}$ & 1800 & $270.000,00$ & \\
& Ag. Halus (Pecahan kaca) & 5,429 & $\mathrm{~kg}$ & 2579 & $250.000,00$ & \\
& $\quad$ Total volume material & 50,341 & $\mathrm{~kg}$ & \multicolumn{2}{c}{ Total harga } & $17.113,00$ \\
\hline & Semen & 7,492 & $\mathrm{~kg}$ & 3150 & $4.410 .000,00$ & $10.488,00$ \\
& Air & 4,345 & $\mathrm{~kg}$ & 1000 & $10.000,00$ & 43,00 \\
$\mathrm{BWG}_{4}$ & Ag. Halus (pasir Muntilan) & 20,407 & $\mathrm{~kg}$ & 1400 & $285.000,00$ & $4.154,00$ \\
& Ag. Kasar (Batu Split) & 12,668 & $\mathrm{~kg}$ & 1800 & $270.000,00$ & $1.357,00$ \\
& Ag. Halus (Pecahan kaca) & 5,429 & $\mathrm{~kg}$ & 2579 & $250.000,00$ & 877,00 \\
& $\quad$ Total volume material & 50.341 & $\mathrm{~kg}$ & Total harga \\
\end{tabular}

\section{Hasil}

\subsection{Hasil uji eksperimental}

Penelitian ini dilakukan secara eksperimental yang dilakukan di PT Tugu Beton Semesta Abadi yang terletak di Jl. Pelabuhan Kendal No. 100, Desa Wonorejo, Kec. Kaliwungu, Kab. Kendal, Jawa Tengah-Indonesia.

\subsection{Pengujian Agregat Halus}

Kegiatan Pengujian material agregat halus bermaksud untuk mengetahui sifat dan karakteristik Pasir Muntilan yang nantinya akan dipakai untuk campuran beton.
Pengujian material agregat halus meliputi uji berat jenis dan penyerapan agregat halus, analisa saringan (Modulus Halus), kadar lumpur dan berat isi [20]. Hasil pengujian material agregat halus adalah sebagai berikut. Pengujian berat jenis dan penyerapan air agregat halus bertujuan untuk memperoleh angka berat jenis curah, berat jenis jenuh kering permukaan (SSD), berat jenis semu, dan angka penyerapan air pada agregat halus. Hasil analisis pengujian berat jenis dan penyerapan air agregat halus dapat dilihat pada Tabel 4.

Tabel 4. Pengujian penyerapan air Agregat halus

\begin{tabular}{lcccc}
\hline \multicolumn{1}{c}{ Uraian } & Satuan & Sampel 1 & Sampel 2 & Rata-rata \\
\hline Berat Pasir SSD & gram & 500 & 500 & 500 \\
Berat pasir kering mutlak (Bk) & gram & 480 & 485 & 482,50 \\
Berat Piknometer + Air + Pasir (Bt) & gram & 1195 & 1200 & 1197,50 \\
Berat Piknometer Berisi Air (B) & Gram & 890 & 890 & 890 \\
Berat jenis Curah Bk/(B+500-Bt) & - & 2,46 & 2,55 & 2,51 \\
Berat Jenis SSD 500/(B+500-Bt) & - & 2,56 & 2,63 & 2,60 \\
Berat Jenis Semu Bk/(B+Bk-Bt) & - & 2,74 & 2,77 & 2,76 \\
Penyerapan Air (500-Bk)/Bk*100\% & persen & 4,17 & 3,09 & 3,63 \\
\hline
\end{tabular}

Tabel 5. Pengujian Agregat Kasar (Batu Split)

\begin{tabular}{lcccc}
\hline \multicolumn{1}{c}{ Uraian } & Satuan & Sampel 1 & Sampel 2 & Rata-rata \\
\hline Berat kerikil SSD (B) & gram & 1000 & 1000 & 1000 \\
Berat kerikil kering mutlak (Bk) & gram & 990 & 988 & 989 \\
Berat kerikil dalam air (Ba) & gram & 632 & 628 & 630 \\
Berat jenis Curah Bk/(Bj-Ba) & gram & 2,69 & 2,66 & 2,67 \\
Berat Jenis SSD BJ/(Bj-Ba) & - & 2,72 & 2,69 & 2,70 \\
Berat Jenis Semu Bk/(Bk-Ba) & - & 2,77 & 2,74 & 2,75 \\
Penyerapan Air (Bj-Bk)/Bk*100\% & - & 1,01 & 1,21 & 1,11 \\
\hline
\end{tabular}

Gradasi pasir muntilan tidak terlalu jauh melewati ambang batas yang telah ditentukan, Pasir muntilan masuk kedalam gradasi pasir Daerah II, untuk modulus halus butir didapatkan nilai sebesar 2,51\%, nilai tersebut masih 
masuk kedalam syarat SNI 03-1968-1990 yakni sebesar $1,5 \%-3,8 \%$.

Kegiatan Pengujian material agregat kasar bertujuan untuk mengetahui sifat dan karakteristik dari batu split dan limbah pecahan kaca yang nantinya akandipakai untuk campuran beton. Pengujian material agregat kasar meliputi uji beratjenis dan penyerapan agregat kasar (batu split) [21], analisa saringan (Modulus Halus) batu split, kadar lumpur (batu split) dan berat isi (batu split dan waste glass). Hasil pengujian material agregat kasar adalah sebagai berikut.

\subsection{Pengujian Berat isi Agregat Kasar (Waste Glass)}

Sama seperti Pengujian berat isi agregat kasar batu split pengujian agregat kasar waste glass dibagi menjadi dua juga, yaitu pengujian berat isi gembur dan berat isi padat. . Hasil pengujian berat isi gembur dan padat agregat kasar waste glass sebagaimana pada Tabel 6 dimana skema pengujian ini dilaksanakan di laboratorium dengan banyak variabel pengendali pada penelitian yang telah dilaksanakan.

Tabel 6. Pengujian Agregat Kasar Waste Glass

\begin{tabular}{lcc}
\hline \multicolumn{1}{c}{ Uraian } & Satuan & Hasil Pengujian \\
\hline Berat tabung $\left(\mathrm{W}_{1}\right)$ & gram & 2450 \\
Berat tabung + agregat kering tungku $\left(\mathrm{W}_{2}\right)$ & gram & 10295 \\
Berat agregat $\left(\mathrm{W}_{3}\right)$ & gram & 7845 \\
Volume tabung $(\mathrm{V})$ & $\mathrm{cm}^{3}$ & 6612,84 \\
Berat isi gembur $\left(\mathrm{W}_{3} / \mathrm{V}\right)$ & $\mathrm{gram} / \mathrm{cm}^{3}$ & 1,19 \\
\hline
\end{tabular}

\subsection{Pengujian Agregat Kasar}

Hasil pengujian di atas menghasilkan berat isi gembur agregat halus sebesar $1,370 \mathrm{gram} / \mathrm{cm}^{3}$, dan berat isipadat agregat halus adalah sebesar $1,450 \mathrm{gram} / \mathrm{cm}^{3}$. Hal ini berarti bahwa berat isi agregat kasar yang digunakan cukup baik untuk bahan campuran beton.karena selisih antara berat isi gembur dengan berat isi padat tidak terlalu jauh, yaitu sebesar $0,070 \mathrm{gr} / \mathrm{cm}^{3}$. Sama seperti Pengujian berat isi agregat kasar batu split pengujian agregat kasar waste glass dibagi menjadi dua juga, yaitu pengujian berat isi gembur dan berat isi padat.

\subsection{Pengujian Kuat Tekan Trial Mix}

Percobaan uji campuran dimaksudkan untuk mengidentifikasi apakah komposisi campuran beton yang telah direncanakan bisa mencapai mutu beton rencana yakni sebesar $18 \mathrm{MPa}$ atau tidak. percobaan ini dilakukan dengan membuat benda uji silinder dengan proporsi campuran beton normal mutu k225. Setelah setelah memasuki masa perawatan beton trial mix akan di uji ketika betonberumur 7 hari, 14 hari dan 28 hari. Jika hasil pengujian kuat tekan beton tidak mencapai $18 \mathrm{MPa}$, maka

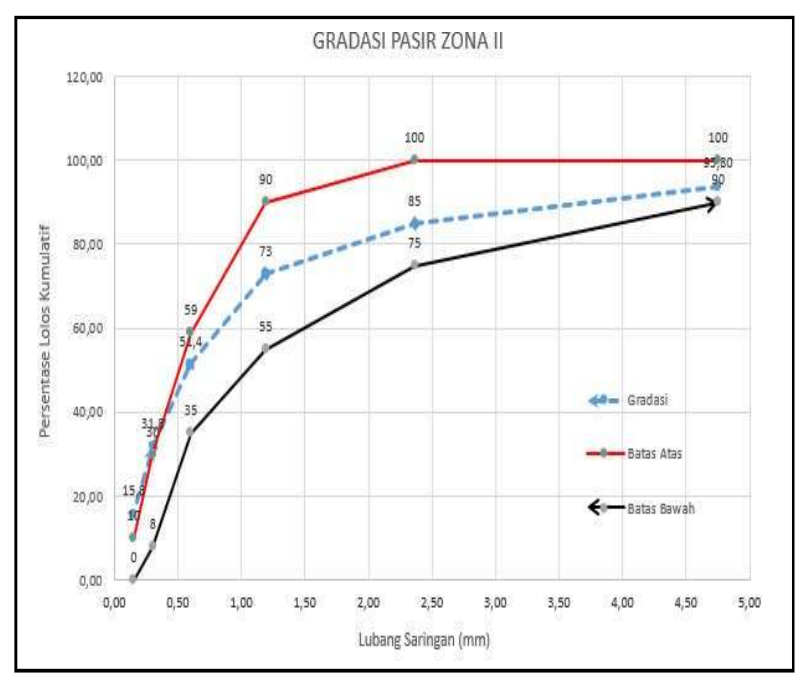

Gambar 4. Grafik Gradasi Agregat Halus (Pasir Muntilan) peneliti akan menambahkan proporsi campuran semen pada perhitungan komposisi campuran beton agar mutu beton tercapai. Dan apabila dalam pelaksanan pengujian kuat tekan beton $18 \mathrm{Mpa}$ sudah bisa tercapai maka penelitian dilanjutkan pada proses pembuatan benda uji yang berjumlah 15 buah. Berikut adalah hasil pengujian slump dan kuat tekan beton trial mix mutu k225 atau 18 $\mathrm{MPa}$.

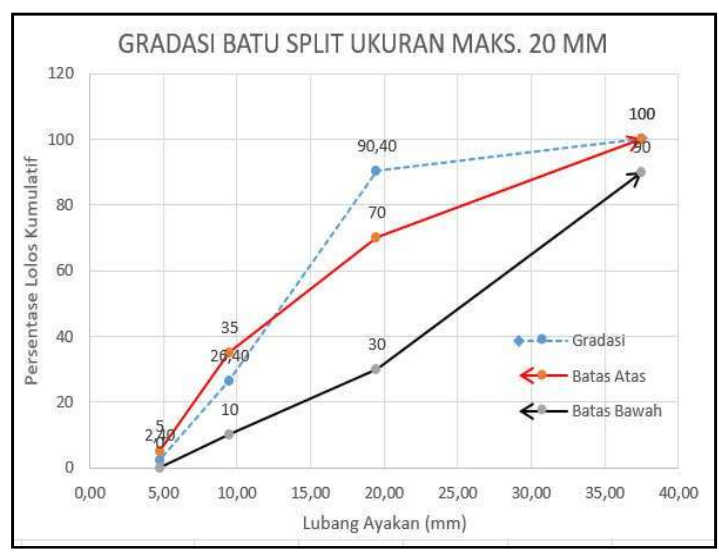

Gambar 5. grafik gradasi batu split untuk lubang ayakan $19,50 \mathrm{~mm}$ 
Grafik gradasi batu split untuk lubang ayakan 19,50 mm hasil pengujian melampaui batas atas persen lolos kumulatif tetapi untuk hasilnilai modulus halus butir didapatkan nilai sebesar 7,19\%, nilai tersebut masih masuk kedalam syarat SNI 03-1968-1990 yakni sebesar $5 \%-8 \%[22]$.

\subsection{Hasil Pengujian Beton Normal}

Dari hasil pengujian pada Gambar 6 kuat tekan beton normalmenunjukan nilai kuat tekan beton umur 7 hari menghasilkan nilai 20,95 N/mm², dan beton berumur 14 hari menghasilkan nilai kuat tekan 28,31 N/mm², dari hasil perbandingan kuat tekan beton umur 7 hari dan 14 hari, kuat tekan beton mengalami peningkatan kuat tekan sebesar 26\%, dan untuk hasil uji kuat tekan beton maksimum pada umur 28 hari menghasilkan nilai kuat tekan sebesar $34,54 \mathrm{~N} / \mathrm{mm}^{2}$, nilai kuat tekan tersebut mengalami peningkatan sebesar $18 \%$ dari beton umur 14 hari.

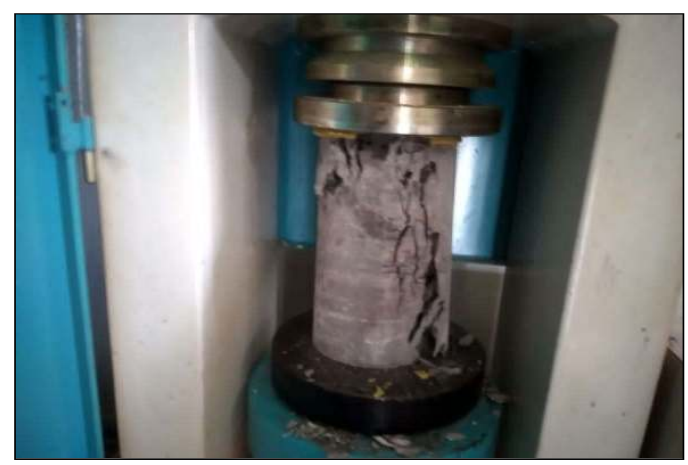

Gambar 6. Pengujian silinder beton Normal

\subsection{Beton BWG 5\%}

Dari hasil pengujian pada Gambar 7 kuat tekan beton waste glass 5\% menunjukan nilai kuat tekan beton umur 7 hari menghasilkan nilai24,35 N/mm², dan beton berumur 14 hari menghasilkan nilai kuat tekan25,48 N/mm² dari hasil perbandingan kuat tekan beton umur 7 hari dan 14 hari, kuat tekan beton mengalami peningkatan sebesar $4 \%$, dan untuk hasiluji kuat tekan beton maksimum pada umur 28 hari menghasilkan nilai kuattekan sebesar 33,97 $\mathrm{N} / \mathrm{mm}^{2}$, naik sebesar $25 \%$ dari beton umur 14 hari.

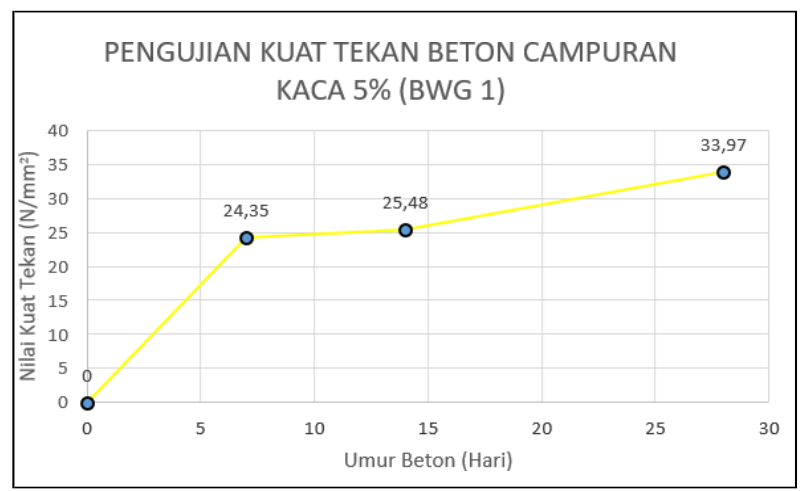

Gambar 7. Hasil Pengujian Beton BWG 5\%

\subsection{Beton BWG 15\%}

Dari hasil pengujian pada Gambar 8 kuat tekan Beton Waste Glass 15\% menunjukan nilai kuat tekan beton umur 7 hari menghasilkan nilai $17,55 \mathrm{~N} / \mathrm{mm}^{2}$, dan beton berumur 14 hari menghasilkan nilai kuat tekan 23,78 $\mathrm{N} / \mathrm{mm}^{2}$ dari hasil perbandingan kuat tekan beton umur 7 hari dan 14 hari, kuat tekan beton mengalami peningkatan sebesar 26\%, dan untuk hasil uji kuat tekan beton maksimum pada umur 28 hari menghasilkan nilai kuat tekan sebesar $29,44 \mathrm{~N} / \mathrm{mm}^{2}$, naik sebesar $19 \%$ dari beton umur 14 hari.

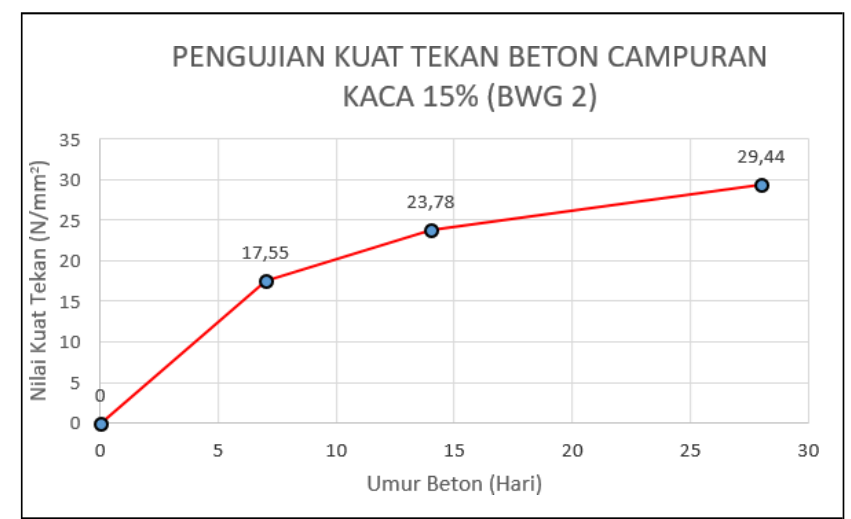

Gambar 8. Hasil uji kuat tekan beton BWG 15\%.

\subsection{Beton BWG 15\%}

Dari hasil pengujian Gambar 9 kuat tekan Beton Waste Glass 30\%menunjukan nilai kuat tekan beton umur 7 hari menghasilkan nilai $20,38 \mathrm{~N} / \mathrm{mm}^{2}$, dan beton berumur 14 hari menghasilkan nilai kuat tekan 20,95 N/mm² dari hasil perbandingan kuat tekan beton umur 7 hari dan 14 hari, kuat tekan beton mengalami peningkatan nilai kuat tekan sebesar $2 \%$, dan untuk hasil uji kuat tekan beton maksimum pada umur 28 hari menghasilkannilai kuat tekan sebesar $26,04 \mathrm{~N} / \mathrm{mm}^{2}$, naik sebesar $19 \%$ dari beton umur 14 hari.

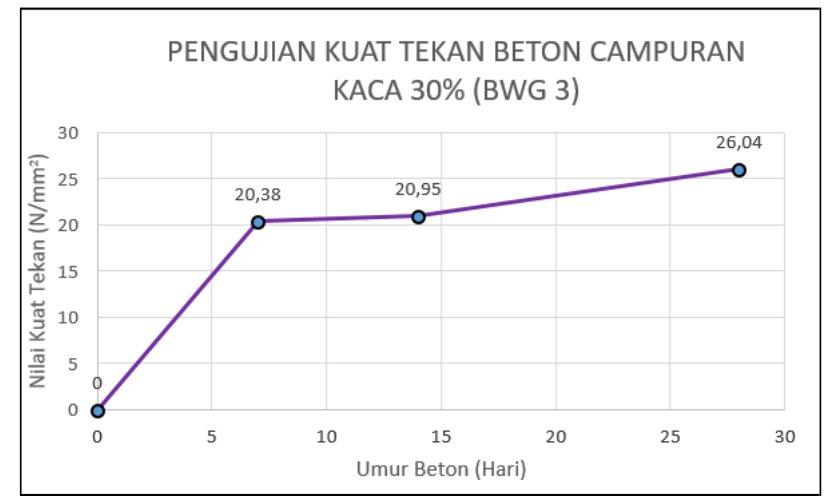

Gambar 9. Pengujian Uji Kuat Tekan Beton BWG 30\%.

\subsection{Hasil Pengujian BWG 50\%}

Dari hasil pengujian pada Gambar 10 kuat tekan Beton 
waste glass $50 \%$ menunjukan nilai kuat tekan beton umur 7 hari menghasilkan nilai $13,02 \mathrm{~N} / \mathrm{mm}^{2}$, dan beton berumur 14 hari menghasilkan nilai kuat tekan 19,82 $\mathrm{N} / \mathrm{mm}^{2}$ dari hasil perbandingan kuat tekan beton umur 7 hari dan 14 hari, kuat tekan beton mengalami peningnkatan nilai kuat tekan sebesar 34\%, danuntuk hasil uji kuat tekan beton maksimum pada umur 28 hari menghasilkannilai kuat tekan sebesar 22,08 N/mm², naik sebesar $10 \%$ dari beton umur 14 hari.

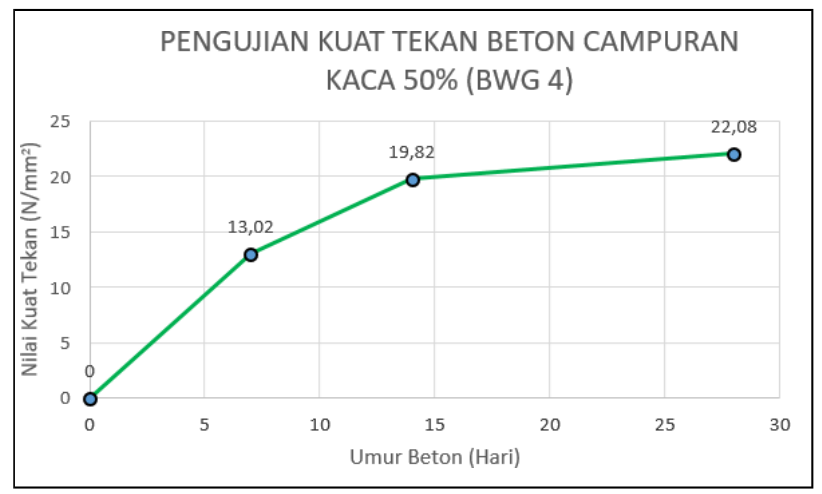

Gambar 10. Pengujian Uji Kuat Tekan Beton BWG 50\%

\subsection{Analisa Perbandingan Kuat Tekan Beton Normal dan Kuat Tekan Beton BWG}

Perbandingan hasil pengujian kuat tekan pada tiap-tiap varian benda uji bertujuan untuk melihat dan membandingakan beton normal dengan beton perlakuan penambahan agregat pecahan limbah kaca.

Dari hasil analisa pada Gambar 11 Diagram grafik menunjukan pada pengujian benda uji umur 7 hari Beton Waste Glass 5\% (BWG $)_{1}$ mendapatkan nilai kuat tekan paling tertinggi dengan nilai 24,35 N/mm², di ikuti Beton Normal 20,95 N/mm², Beton Waste Glass 30\% (BWG 3 ) 20,38 N/mm², Beton Waste Glass 15\% (BWG $\left.{ }_{2}\right) 17,55$ $\mathrm{N} / \mathrm{mm}^{2}$, dan Beton Waste Glass 50\% (BWG 4$)$ 13,02 $\mathrm{N} / \mathrm{mm}^{2}$

Untuk hasil umur 14 hari Beton Normal (BN) memperoleh hasil yang tertinggi dengan hasil kuat tekan 28,31 N/mm², di ikuti Beton Waste Glass 5\% (BWG $)_{1}$ 25,48 N/mm², Beton Waste Glass 15\% (BWG $\left.{ }_{2}\right) 23,78 \mathrm{~N} / \mathrm{mm}^{2}$, Beton Waste Glass 30\% (BWG ${ }_{3}$ ) 20,95 N/mm² , dan Beton Waste Glass $50 \%\left(\mathrm{BWG}_{4}\right)$ mendapatkan hasil yang paling rendah dengan hasil nilai kuat tekan $19,82 \mathrm{~N} / \mathrm{mm}^{2}$. Untuk hasil pengujian 28 hari Beton Normal (BN) memperoleh hasil yang tertinggi dengan hasil kuat tekan 34,58 N/mm², di ikuti Beton Waste Glass 5\% (BWG $)$ 33,97 N/mm², Beton Waste Glass 15\% $\left(\mathrm{BWG}_{2}\right) 29,44 \mathrm{~N} / \mathrm{mm}^{2}$, Beton Waste Glass 30\% (BWG 3 ) 26,04 N/mm², dan Beton Waste
Glass $50 \%\left(\mathrm{BWG}_{4}\right)$ mendapatkan hasil kuat tekan 22,08 $\mathrm{N} / \mathrm{mm}^{2}$.

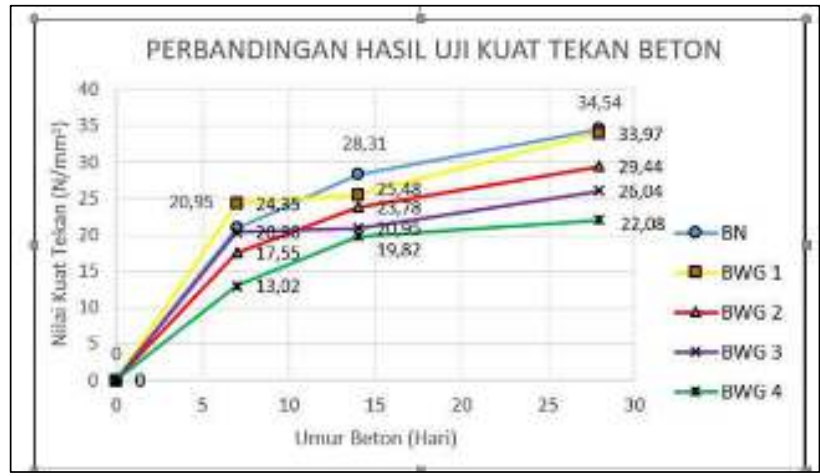

Gambar 11. Perbandingan Hasil Uji Kuat Tekan Beton

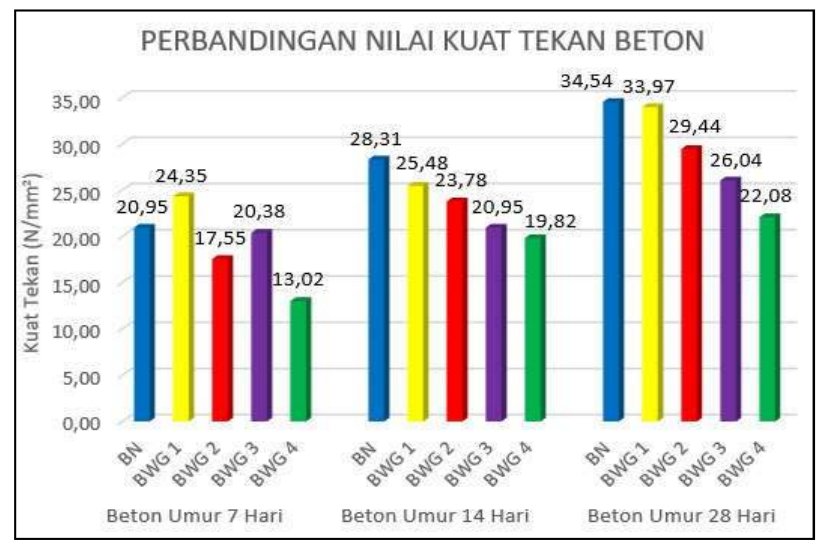

Gambar 12. Diagram batang Perbandingan Beton Normal dan Beton BWG

Hasil analisa perbandingan kuat tekan Beton Normal dengan Beton Waste Glass untuk pengujian 7 hari menunjukan beton $\mathrm{BWG}_{1}$ mengalami peningkatan kuat tekan sebesar $16 \%$ dibandingkan $\mathrm{BN}$, hal ini bisa disebabkan karena isi dari benda uji terlalu banyak mengandung agregat kasar batu split, sedangkan untuk benda uji lain mengalami penurunan nilai kuat tekan dibandingankan $\mathrm{BN}$ dengan penurunan yang beragam mulai dari $\mathrm{BWG}_{2}$ mengalami penurunan $16 \%$, beton $\mathrm{BWG}_{3}$ penurunan $3 \%$, dan $\mathrm{BWG}_{4}$ mengalami penurunan yang terbesar yaitu sebesar $38 \%$.

Analisa perbandingan kuat tekan Beton Normal dengan Beton Waste Glass untuk pengujian 14 hari menunjukan beton $\mathrm{BWG}_{1}$ mengalami penurunansebesar $10 \%, \mathrm{BWG}_{2}$ sebesar $16 \%, \mathrm{BWG}_{3}$ sebesar $26 \%$, dan $\mathrm{BWG}_{4}$ sebesar $30 \%$. Perbandingan kuat tekan beton maksimum untuk Beton Normal dengan Beton Waste Glass dalam pengujian 28 hari menunjukan beton BWG 1 mengalami penurunan sebesar $2 \%, \mathrm{BWG}_{2}$ sebesar $15 \%, \mathrm{BWG}_{3}$ sebesar 25\%,dan BWG 4 sebesar 36\% dibanding BN. 
Dari seluruh hasil pengujian kuat tekan beton umur 7 hari, 14 hari dan 28 hari, hasil perbandingan nilai kuat tekan beton waste glass 5\%, 15\%, 30\%, dan50\% dengan beton normal kecuali untuk yang beton waste glass $5 \%$ pengujian 7 hari, seluruh benda uji mengalami penurunan nilai kuat tekan beton. Semakin banyak penambahan kaca nilai kuat tekannya akan semakin menurun bisa di lihatpada hasil pengujian kuat tekan pada Gambar 12 penurunan kuat tekan dipengaruhi oleh kandungan kaca yang ada pada campuran beton mengalamipemuaian ditambah dengan bentuk kaca yang tidak memiliki pori-pori membuat kaca tidak bisa mengikat agregat halus, air dan semen secara sempurna dibandingkan dengan batu split.

\section{Simpulan}

Dari hasil pengujian kuat tekan beton pada tiap-tiap varian campuran beton yang telah dilakukan dapat disimpulkan sebagai berikut: Pemanfaatan Waste Glass sebagai pengganti agregat kasar pada beton mutu K-225 dalam campuran adukan beton merupakan inovasi yang efektif untuk menekan biaya pembuatan beton sekaligus mengurangi limbah kaca yang tidak terpakai/ sulit di daur ulang.

Hasil perbandingan uji tekan beton normal dengan beton campuran agregat kasar (waste glass) 5\%, 15\%, 30\%, dan $50 \%$ mutu K-225 mengalami perbedaan nilai kuat tekan, seiring penambahan persentase agregat pecahan kaca, sehingga dibutuhkan proporsi campuran yang tepat agar memperoleh nilai kuat tekan yang maksimal. Pemakaian perbandingan campuran adukan beton 1 semen, 3 agregat halus, dan 3 agregat kasar (1:3:3) dengan Faktor Air Semen (f.a.s) 0,58 untuk mutu beton k225 melebihi target dari nilai kuat tekan beton yang telah direncanakan.

Hasil data pengujian kuat tekan beton umur 7 hari,14 hari dan 28 hari diperolehnilai kuat tekan Beton Normal: 20, $28 \mathrm{MPa}$, dan $34 \mathrm{MPa}$, beton waste glass 5\%: 24MPa, 25 $\mathrm{MPa}$, dan $33 \mathrm{MPa}$, beton waste glass 15\%: 17, 23, dan $29 \mathrm{~N} / \mathrm{mm}^{2}$, beton waste glass 30\%: $20 \mathrm{MPa}, 20 \mathrm{MPa}$, dan $26 \mathrm{MPa}$, serta beton waste glass $50 \%: 13 \mathrm{MPa}, 19 \mathrm{MPa}$, dan $22 \mathrm{MPa}$.

Beton waste glass 5\% merupakan proporsi campuran beton kaca yang mempunyai nilai kuat tekan tertinggi dibandingkan dengan proporsi pecampuran kaca 15\%, $30 \%$ dan $50 \%$, karena hasil uji kuat tekan beton tersebut mendekati hasil kuat tekan Beton Normal.

\section{Daftar Rujukan}

[1] A. Setiawan, Perancangan Struktur Beton Bertulang (Berdasarkan SNI 2847:2013) Edisi I, 1st ed.
Jakarta: Erlangga., 2016.

[2] Badan Standardisasi Nasional, SNI 2847:2013. Persyaratan Beton Struktural untuk bangunan Gedung. Jakarta: Badan Standardisasi Nasional, 2013.

[3] I. Dipohusodo, Struktur Beton Bertulang (Berdasarkan SK SNI T-15-1991-03 Departemen Pekerjaan Umum RI), 1st ed. Yogyakarta: Gramedia Pustaka Utama, 1994.

[4] A. Santoso, S. Widodo, and F. Ma, "4. Pemanfaatan Limbah Styrofoam (Expanded Polysterene) untuk Pembuatan Dinding Struktural Beton Ringan Ramah Lingkungan," Inersia : Jurnal Teknik Sipil dan Arsitektur, vol. 7, no. 1, May 2011, doi: 10.21831/INERSIA.V7I1.3701.

[5] F. Ma'arif, Z. Gao, and F. Li, "Investigation of concrete quality using Discrete Element Method (DEM)," Journal of Physics: Conference Series, vol. 1833, no. 1, p. 012053, Mar. 2021, doi: 10.1088/1742-6596/1833/1/012053.

[6] A. Santoso, S. Widodo, and F. Ma'arif, "Prediction of Lighweight Concrete Panel Homogeneity by Ultrasonic Pulse Velocity (UPV),” pp. 1-7, Sep. 2017, doi: 10.2991/ICTVT-17.2017.1.

[7] F. Ma'Arif, Z. Gao, F. Li, and H. U. Ghifarsyam, "The New Analysis of Discrete Element Method Using ARM Processor," IOP Conference Series: Earth and Environmental Science, vol. 832, no. 1, p. 012016, Jul. 2021, doi: 10.1088/17551315/832/1/012016.

[8] N. H. Aswad and T. S. Soeparyanto, "Penggunaan Pecahan Botol Kaca Sebagai Agregat Kasar Pada Campuran Beton," Jurnal Stabilita, vol. 2, no. 1, pp. 101-108, 2014.

[9] A. Mulyadi, Diawarman, and Ricih, "Analisis Pengaruh Penambahan Limbah Pecahan Kaca Terhadap Campuran Beton Mutu K-175," Jurnal Unpal, vol. 1, no. 1, pp. 6-12, 2018.

[10] M. Liaqat, M. L. Shah, and M. A. Baig, "Effect of Waste Glass as Partial Replacement for Coarse Aggregate in Concrete," International Journal of Technical Innovation in Modern Engineering \& Science, vol. 4, no. 6, pp. 609-619, 2018.

[11] P. Meilita, Azizah, I. A. Resti, and R. G. Lina, "Industri Kaca," INA-Rxiv Papers, vol. 1, no. 1.

[12] U. Tomas and J. Ganiron, "The Effect of Waste Glass Bottles as an Alternative Coarse Aggregate in Concrete Mixture," International Journal of ICTaided Architecture and Civil Engineering, vol. 1, no. 2, pp. 1-10, 2014.

[13] S. Valand, K. K. Singh, H. Pathak, and G. Deshpande, "Performance Evaluation of Concrete by using Waste Glass," International Research Journal of Engineering and Technology (IRJET), vol. 5, no. 8, pp. 824-827, 2018.

[14] T. Mulyono, Teknologi Beton. Yogyakarta: Andi, 2005.

[15] K. Tjokrodimuljo, Teknologi Beton. Yogyakarta: NAFIRI, 1996.

[16] ASTM International, ASTM International - ASTM 
C39/C39M-20 Standard Test Method for Compressive Strength of Cylindrical Concrete Specimens. 2020.

[17] Badan Standardisasi Nasional, SNI 03-3449-2002. Tata Cara Rencana Pembuatan Campuran Beton Ringan Dengan Agregat Ringan. Jakarta: Badan Standardisasi Nasional, 2002.

[18] Badan Standardisasi Nasional, SNI 03-2834-2000. Tata Cara Pembuatan Rencana Campuran Beton Normal. Jakarta: Badan Standardisasi Nasional, 2000 .
[19] Badan Standardisasi Nasional, SNI 1972:2008. Cara Uji Slump Beton. Jakarta: Badan Standardisasi Nasional, 2008.

[20] B. S. Nasional, SNI 1970:2008. Cara Uji Berat Jenis dan Penyerapan Air Agregat Halus. Jakarta: Badan Standardisasi Nasional, 2008.

[21] Badan Standardisasi Nasional, SNI 1969:2008. Cara Uji Berat Jenis dan Penyerapan Air Agregat Kasar. Jakarta: Badan Standardisasi Nasional, 2008.

[22] Badan Standardisasi Nasional, SNI 03-1968-1990 Metode Pengujian Analisis Saringan Agregat Kasar dan Agregat Halus. 1990. 